conduct research in the primary health care sitting. Many barriers to conduct research were identified the three most highly rated barrier was no access to research fund. Limited training in research methodology and limited support were the next most highly rated barriers. Barriers found to be significantly associated with research willingness were limited time, no access to the fund and lack of experience in conducting Research.

Conclusions The study shows that PHC physicians are willing and have a positive attitude towards primary health care research but face many obstacles. The key obstacles are limited time, no access to fund, and lack of experience.

\section{STRUCTURED LIGHT PLETHYSMOGRAPHY, A NON INVASIVE, NON CONTACT METHOD OF RECORDING RESPIRATORY FUNCTION}

doi:10.1136/archdischild-2012-302724.0145

R lles. Respiratory Paediatrics, Addenbrooke's Hospital, Cambridge, UK

Structured light plethysmography (SLP) technology utilises pc gaming/movie techniques to scan a patient with visible light, capture an image, measure movement in the image and produce accurate, real time data on changes in respiration. A checker board pattern of light is projected from a light projector onto the chest of an individual. Movements of the grid are viewed by two digital cameras, digitalised, and processed to form a 3D model and can be interrogated to assess lung function. The system has been tested in normal adults and children, adults with COPD, and children with cystic fibrosis.

Most recently it has been used to measure respiratory patterns in healthy infants, within 24 hours of birth, those born prematurely with and without chronic lung disease (CLD). The infants are not sedated, but simply placed, bare chested, within the field of vision of the Thora3DI (Pneumacare ${ }^{\mathrm{TM}}$, Cambridge UK). There is no physical contact with the infant. This has not just one, but repeated data collection over short periods of time, on oxygen dependent infants with severe CLD, without changes in oxygen requirement or periods of clinical instability. Information on respiratory rate, tidal volume and the relationship between chest and abdominal volume change have been assessed, and will be included in this presentation.

Dr. Richard Iles is a Consultant in Respiratory Paediatrics, and founder and shareholder of PneumaCare Ltd, the Company that produces the Thora3DI.

\section{LUNG VOLUME IN VERY PRETERM INFANTS WITH EARLY RESPIRATORY DISTRESS SYNDROME (RDS) RECEIVING NASAL CONTINUOUS POSITIVE AIRWAY PRESSURE (CPAP)}

doi:10.1136/archdischild-2012-302724.0146

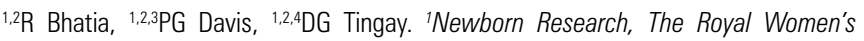
Hospital, Parkville; 'Neonatal Research, Murdoch Childrens Research Institute; ${ }^{3}$ Department of Obstetrics and Gynaecology; ${ }^{4}$ Department of Paediatrics, University of Melbourne, Melbourne, VIC, Australia

Background and aims Although CPAP is extensively used for early RDS in very preterm infants from birth, the influence of CPAP on lung behaviour in early illness remains unclear. This study aimed to describe global volumetric behaviour and work of breathing (WOB) at differing continuous distending pressures (CDP) in very preterm infants in the first 12-18 hrs of life.

Methods Infants $<32$ weeks' gestational age receiving nasal CPAP from birth were studied whilst supine. Data were initially recorded at the CPAP in clinical use [baseline; mean (SD) $6(1) \mathrm{cmH}_{2} \mathrm{O}, \mathrm{FiO}_{2}$ $0.25(0.03)]$. Then, CPAP was applied at 5, 8, 10 and $8 \mathrm{cmH}_{2} \mathrm{O}$ for 15 -mins each. Changes in end-expiratory lung volume $[\Delta \mathrm{EELV}$
$\left(\mathrm{V}_{\mathrm{T}}\right.$ units $\left.)\right]$ and tidal volume $\left[\Delta \mathrm{V}_{\mathrm{T}}\left(\mathrm{V}_{\mathrm{T}}\right.\right.$ units $\left.)\right]$ were measured using respiratory inductive plethysmography and expressed relative to values obtained at CPAP $5 \mathrm{cmH}_{2} \mathrm{O}$. Breath-to-breath phase angles $(\Theta)$ and labour breathing index (LBI) were calculated post-hoc to determine respiratory asynchrony.

Results Twenty infants, mean(SD) GA 29(1) weeks and BW 1181(417)g were studied at median (IOR) 15(13.16)hours. No significant differences were seen in global EELV, $V_{\mathrm{T}}, \mathrm{WOB}$ or LBI at all CDP. Only 11/20 infants demonstrated hysteresis with a significant increase in EELV from baseline following a CPAP recruitment manoeuvre.
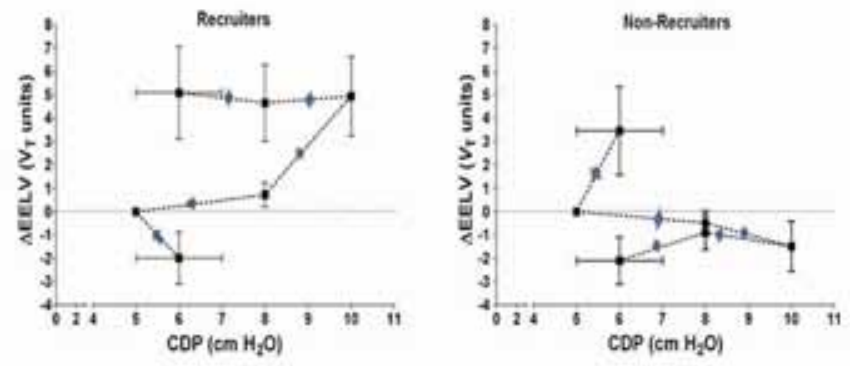

Abstract 146 Figure 1 Change in EELV in Recruiters vs. Non-Recruiters

Conclusions Not all preterm infants have recruitable lung disease. Infants with recruitable lung disease may benefit from a CPAP recruitment manoeuvre. Further work is needed to define the optimal CPAP level to use in early RDS.

\section{LOSS OF END-EXPIRATORY LUNG VOLUME DURING PERIODS OF HYPOPNOEA IN PRETERM INFANTS WITH EARLY RESPIRATORY DISTRESS SYNDROME (RDS) RECEIVING CPAP}

doi:10.1136/archdischild-2012-302724.0147

${ }^{1,2}$ R Bhatia, ${ }^{1,2,3} \mathrm{PG}$ Davis, ${ }^{1,2,4} \mathrm{DG}$ Tingay. 'Newborn Research, The Royal Women's Hospital, Parkville; 'Neonatal Research, Murdoch Children's Research Institute; ${ }^{3}$ Department of Obstetrics and Gynaecology; ${ }^{4}$ Department of Paediatrics, University of Melbourne, Melbourne, VIC, Australia

Background and aims Whether variations in end-expiratory lung volume (EELV) occur in stable infants receiving nasal CPAP is unknown. This study aimed to describe global and regional volumetric behavior over periods of hypopnoea ( $<20$ breaths/min over 15 -secs) in preterm infants $<18$ hours of age receiving nasal CPAP. Methods Twenty infants $<32$ weeks' receiving CPAP were studied whilst supine. Clinicians set CPAP level at mean(SD) $6(1) \mathrm{cmH}_{2} \mathrm{O}$ in $\mathrm{FiO}_{2} 0.25(0.03)$. Relative $\triangle \mathrm{EELV}$ and tidal volume $\left(V_{\mathrm{T}}\right)$ [respiratory inductive plethysmography] ] and regional $\Delta$ EELV [electrical impedance tomography] were measured. 20-secs of data were analysed preceding and following episodes of hypopnoea and $\Delta$ EELV and $\Delta V_{\mathrm{T}}$ determined (expressed as average $V_{\mathrm{T}}$ units at baseline). Breath-tobreath phase angles $(\Theta)$ and labored breathing index (LBI) were calculated post-hoc.

Results Ten episodes of hypopnoea lasting mean(SD) 26(11)s were analyzed in 10 infants mean(SD) GA 29(1) weeks and BW 1119 (264)g. EELV and $V_{\mathrm{T}}$ fell significantly from baseline by median(range) $0.3(-1.1,0.5)$ and $0.2(0.3) V_{\mathrm{T}}$ units $(\mathrm{p}<0.05)$ during episodes of hypopnoea. Both non-dependant and dependant halves of the chest contributed equally to global loss in EELV during hypopnoea. During recovery, the non-dependant hemi-thorax recovered median (range) $70(9,100) \%$ and dependant $63(4,100) \%$ of the loss of EELV in those regions respectively. No changes were seen in HR, oxygen saturations, $\mathrm{FiO}_{2}$, LBI and thoraco-abdominal asynchrony during these episodes. 